\title{
Environmental Impact Assessment, Human Health and the Sustainable Development Goals
}

\author{
G. Gulis $^{1 *}$, N. Krishnankutty ${ }^{1}$, E. R. Boess ${ }^{2,3}$, I. Lyhne ${ }^{3}$ and L. Kørnøv ${ }^{3}$ \\ ${ }^{1}$ Unit for Health Promotion Research, University of Southern Denmark, Esbjerg, Denmark, ${ }^{2}$ COWl, Lyngby, Denmark, ${ }^{3}$ Danish \\ Centre for Environmental Assessment, Aalborg University, Aalborg, Denmark
}

Objectives: Developmental processes influence the determinants of health and, consequently, human health. Yet, assessing human health impacts in impact assessment, with exception of health impact assessment, is still rather vague. Inclusion of Sustainable Development Goal indicators in environmental impact assessment (EIA) is an opportunity to enhance addressing human health in EIA practices.

Methods: We reviewed a list of health-related targets and indicators for SDGs as defined by the Institute of Health Metrics and Evaluation (IHME) in Seattle, WA, United States with the aim of identifying those to be suggested as outcome indicators within EIA.

Results: Among 42 health-related indicators, we identified 17 indicators which could be relevant for impact assessment procedures and categorized them into three groups: 1)

OPEN ACCESS

Edited by:

Nino Kuenzli

Swiss Tropical and Public Health Institute (Swiss TPH), Switzerland

Reviewed by:

Jean Simos,

Université de Genève, Switzerland

*Correspondence:

G. Gulis

ggulis@health.sdu.dk

This Original Article is part of the IJPH Special Issue "Health in All Sustainable Development Goals"

Received: 20 August 2021 Accepted: 03 January 2022 Published: 31 January 2022

Citation:

Gulis G, Krishnankutty N, Boess ER, Lyhne I and Kørnøv L (2022) Environmental Impact Assessment, Human Health and the Sustainable Development Goals. Int J Public Health 67:1604420. doi: 10.3389/ijph.2022.1604420 direct health indicators (e.g., under five mortality). 2) complex indicators (e.g., cancer). 3) environmental determinant indicators (e.g., mean $\mathrm{PM}_{2.5}$ ).

Conclusion: All 17 indicators can be employed to improve quantification assessing human health impacts and bring SDGs into EIA processes. Though our assessment has been conducted for Denmark and the set of suggested indicators could be different for contexts in other countries, the process of their identification can be generalized.

Keywords: population health, SDGs, impact assessment, EIA, indicators

\section{INTRODUCTION}

Environmental impact assessment (EIA), typically understood as project level assessment of a broad set of environmental impacts, has a long-term success history since its first statutory introduction in 1969 [1]. Since then, most countries introduced EIA into their legislation and made it a central tool to improve developmental processes and inform of their impact on environment [2]. Seeing as EIA is a widespread mandatory form of impact assessment, it represents an important arena for uncovering potential human health impacts as part of a broader concept of environment. In this way, the EIA complements Health Impact Assessment (HIA), which is usually a voluntary assessment focusing on potential health risks and benefits. Despite the indivisible link between environment and health, impacts on human health have not been a focus of EIA in the early decades and even health determinants (with the exception of environmental determinants) were rare and narrowly discussed within EIA reports [3]. A major legislative change to this practice occurred in 2014, when the European Commission, via an amendment to the directive (Directive 2014/52/EU), formally introduced impact on human health as a mandatory impact to assess within EIA [4]. Denmark, 


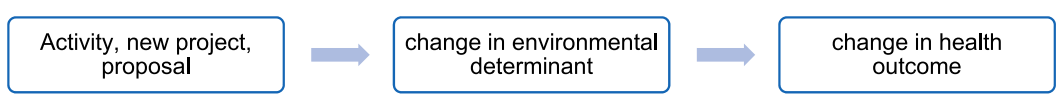

FIGURE 1 | Framework of selection of health indicators. Environmental Impact Assessment, Human Health and the Sustainable Development Goals, Denmark, 2021.

as other European Union countries, implemented the Directive to national legislation making assessment of population health impacts mandatory within EIA [5]. This act provided a requirement to address health more in depth in assessment processes and opened a space for research on tools for assessment and quantification of health impacts. Yet, the historical scope of EIA coupled by a lack of involvement of health expertise in conducting assessments led to the recognition of rather limited inclusion of health in EIA [6-8]. In 2018-19, a reference document was formulated to better address human health in EIA, by the joint venture of International Association for Impact Assessment (IAIA) and the European Public Health Association (EUPHA) [9]. This document constituted that the identification of relevant health impacts, the development of proper indicators to measure them and the assessment of their impacts is a rather complex task. Despite of the guidance provided, the methodological complexities (both qualitative and quantitative methods) are challenging for the non-health professionals who conduct the screening, scoping and especially risk appraisal procedures in EIA [10]. A Danish innovation project "Digitally Supported Environmental Assessment for Sustainable Development Goals-DREAMS" addresses among other issues, inclusion of human health into EIA and Strategic Environmental Assessment (SEA) linking the whole process to the United Nations Sustainable Development Goals (SDGs) [11]. The project aims to explore whether the SDG indicators can be used as target indicators within EIA and SEA. In this article, we focus solely on the project-level assessment within EIA.

The SDGs have provided a global development framework for sustainable development universally applicable to all countries. The 17 goals, 169 targets and 247 unique indicators can be perceived not only as an ambitious set of measures to guide development, but also as an opportunity to compare countries and harmonize processes across different contexts. One of the primary issues with their implementation is how best to operationalize the SDGs in national and local developmental processes, hereunder including environmental assessment procedures. Some authors have proposed that SDGs and environmental assessment can mutually benefit each other, such that SDGs help to provide a sustainable orientation for environmental assessment and bring sustainability objectives into decision-making processes, while environmental assessments simultaneously provide a structured and universally exercised process for measuring SDG fulfillment [12-14]. Yet, the need for localizing the globally developed SDGs remains also a challenge when considering their integration into environmental assessment, and although experimentation in linking SDGs to EIA is beginning to emerge within practice, the integration is predominantly superficial and seemingly disconnected from the potentials constituted through research [12,15]. Literature [16] and practical application cases recently published $[17,18]$ have likewise raised issues with the implementation of SDGs in health impact

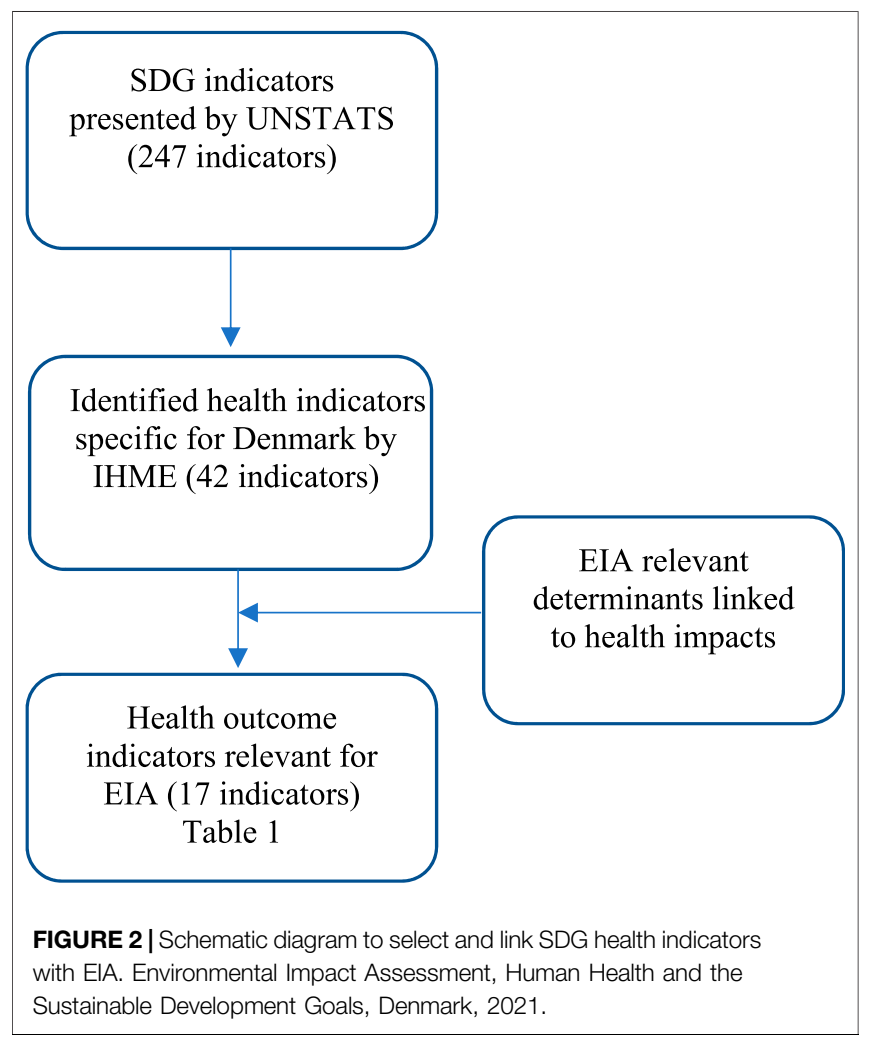

assessment. There is therefore a need for literature to assist in operationalizing the SDGs and guide practice to encourage a productive utilization within impact assessment.

In attempts to better operationalize the SDGs and understand their potential function as decision-support tools, conceptual frameworks to link SDGs with environmental assessment have been developed and published [12, 13]. Inclusion of SDG indicators as target indicators within impact assessment processes seems to be therefore mutually complementary [14]. Some studies have also suggested that the SDGs address sustainability parameters that if applied to environmental assessment, may make for more comprehensive assessments also able to remain current with sustainability agendas [19, 20]. While implying health as a parameter with the potential for improved assessment, few studies have yet specifically focused on elaborating the overlap between health determinants and SDGs, nor have they addressed SDG indicators as a way to support these assessments $[17,18]$.

The aim of our work and this manuscript is to investigate which SDG indicators can support the assessment of health impacts in EIA processes as measures of final health outcomes related to the assessed project. Our focus is on Denmark predominantly, yet we believe the process allows for the generalization to other contexts as well. Our conceptual framework for selection of indicators can be described by this simplified pathway (Figure 1): 
TABLE 1 | List of identified indicators. Environmental Impact Assessment, Human Health and the Sustainable Development Goals, Denmark, 2021.

\begin{tabular}{|c|c|c|c|c|c|}
\hline & $\begin{array}{l}\text { SDG health } \\
\text { INDICATORS }\end{array}$ & Direct & Complex & Environmental & $\begin{array}{l}\text { Environmental risk } \\
\text { factors (relevant } \\
\text { to EIA) }\end{array}$ \\
\hline 1 & 3.2.1. Under-5 mortality & $x$ & & & $\begin{array}{l}\text { Water pollution (micro-pathogens causing diarrhoea), air pollution (carbon } \\
\text { monoxide and fine particulate matter causing pneumonia), high } \\
\text { temperature and humidity }\end{array}$ \\
\hline & 3.4.1. Non communicable disesas mortality & & $x$ & & \\
\hline 2 & a. Cardiovascular disease & $x$ & & & $\begin{array}{l}\text { Exposure to urban air pollution (fine particulate matter), metals (lead, } \\
\text { cadmium, arsenic) }\end{array}$ \\
\hline 3 & b. Cancer & & $x$ & & $\begin{array}{l}\text { Outdoor air pollution, heavy metals, water pollutants (Organic and inorganic } \\
\text { chemicals derived from industrial, commercial and agricultural activities, and } \\
\text { in particular from waste sites, nitrites and nitrates, radionuclides and } \\
\text { asbestos) }\end{array}$ \\
\hline 4 & c. Diabetes & $x$ & & & $\begin{array}{l}\text { Air pollution, physical activity environment and roadways proximity, polluted } \\
\text { air, soil, water }\end{array}$ \\
\hline 5 & d. Chronic respiratory disease & $x$ & & & $\begin{array}{l}\text { Indoor and outdoor air pollutants (Particulate } \mathrm{NO}_{2}, \mathrm{SO}, 03 \text { ) Inorganic dusts } \\
\text { (chalk and talc), fumes and gases (metal, chlorine, } \mathrm{SO}_{2}, \mathrm{H}_{2} \mathrm{~S} \text {, styrene, } \\
\text { polyvinyl chloride/methyl, methacrylate) }\end{array}$ \\
\hline 6 & 3.4.2. Suicide mortality & $x$ & & & \\
\hline 7 & 3.6.1. Road injury mortality & & $\mathrm{x}$ & & Roadways proximity \\
\hline 8 & 3.9.1. Air pollution mortality & & & & $\begin{array}{l}\text { Indoor and outdoor air pollutants (Particulate } \mathrm{NO}_{2}, \mathrm{SO}, \mathrm{O} 3 \text { ) Inorganic dusts } \\
\text { (chalk and talc), fumes and gases (metal, chlorine, } \mathrm{SO}_{2}, \mathrm{H}_{2} \mathrm{~S} \text {, styrene, } \\
\text { polyvinyl chloride/methyl, methacrylate) }\end{array}$ \\
\hline 9 & $\begin{array}{l}\text { 3.9.2. Water, sanitation and hygenie }(\mathrm{WaSH}) \\
\text { mortality }\end{array}$ & & $x$ & & $\begin{array}{l}\text { Water pollutants (Organic and inorganic chemicals derived from industrial, } \\
\text { commercial and agricultural activities, and in particular from waste sites, } \\
\text { nitrites and nitrates, radionuclides and asbestos) }\end{array}$ \\
\hline 10 & 3.9.3. Unintentional poisoning mortality & & $x$ & & \\
\hline 11 & $\begin{array}{l}\text { 6.1.1. Usage of unsafe water, summary } \\
\text { exposure value (SEV) }\end{array}$ & & & $x$ & \\
\hline 12 & 6.2.1a. Unsafe sanitation (SEV) & & & $x$ & \\
\hline 13 & 6.2.1b. Unsafe hygiene & & & $x$ & \\
\hline 14 & 7.1.2. Household air pollution & & & $x$ & Indoor air pollutants (particulate matter) \\
\hline 15 & $\begin{array}{l}\text { 8.8.1. Disability adjusted life years (DALY) due } \\
\text { to occupational burden }\end{array}$ & & $x$ & & \\
\hline 16 & 11.6.2. Mean PM2.5 & & & $x$ & Particulate matter \\
\hline
\end{tabular}

\section{METHODS}

Concrete tools or selection criteria are currently unavailable for selecting or prioritizing relevant health-related SDGs for EIA. Our focus within this work is on project-level EIA; therefore not all SDG health-related targets and indicators may be applicable to review in all EIA projects, as some SDGs and corresponding indicators may pertain more to strategic development than is addressed through a project-level EIA. Since only the indicators substantialize the content of the SDGs and make contributions measurable, it is necessary to select relevant indicators for EIA given a criteria-based approach, which will also aid in narrowing down the 232 SDG indicators that are currently developed on the global plan.

\section{Criteria to Select Relevant Environmental Health SDG Indicators}

Though SDGs are predominantly designed for countries and regions, predefined indicators can be used as guidelines for addressing health aspects in EIA. As a first step, all SDG indicators presented by UNSTATS were considered [21]. The goals, however, are very general and not only applicable to health aspects. In the second step, health-related targets and indicators for SDGs were narrowed down to health-related indicators within a specific country, namely Denmark, by looking at availability of data on indicators in national statistics. Using the metadata of Denmark defined by the Institute of Health Metrics and Evaluation (IHME) in Seattle, WA, United States [22] and Statistics Denmark, health targets and indicators were identified. The third step aimed to identify outcome indicators relevant for EIA. Through an internal expert consultation, we identified those indicators, which can be linked to developmental processes and therefore used within impact assessment. The internal expert consultation consisted of five experts within the field of public health, HIA, environmental health and EIA. The consultation was guided by following protocol:

- We looked at the listing of typology of investment projects subjected to EIA and discussed whether a specific type of investment project can have an impact on environmental determinants of health and selected health indicators.

- We appraised whether the indicator addresses a health outcome or an environmental determinant of health that can be used as part of a causal pathway description. Those measuring health outcomes were classified as either direct or complex health outcomes.

The direct health indicators are considered indicators that can be used directly in assessment, whereas the complex indicators may 
require further break down into more specific health outcomes before being used within EIA. Figure 2 describes the selection flow.

\section{RESULTS}

The analysis of the criteria-based approach to select and link SDG health indicators within EIA identified a wide range of indicators that relate to the health aspects, i.e., physical health; well-being; access to safe amenities; environmental impacts. From among 42 health-related indicators, 17 indicators were identified to be relevant and two indicators potentially relevant for EIA. The list of indicators considered relevant is in Table 1.

The identified relevant health indicators are categorized to reflect how the health indicators are in relation to project activities in EIA, and how the outcome indicators constitute a consideration of human health in EIA. Indicators are categorized as direct indicators, complex indicators and environmental indicators. The direct indicators are the indicators that are affected during either the operational or construction phase of the developmental activity. When calculating the impacts, the direct indicators directly describe the baseline values and estimate the impact. These are, in most cases, part of national demographics or health statistics. They can often be characterized by a code according to International Classification of Diseases-ICD code [23]. The complex indicators are characterized either by merging many determinants into one health outcome, covering a group of individual diseases (e.g., cancer) or by being a composite indicator (e.g., DALY). To apply complex indicators within EIA, a human health expertise is required to estimate cumulative impact derived from the selected indicator, which, in some cases, could also be considered sub-indicators. The third classification is environmental determinant indicators, which describe environmental characteristics or the target area of the assessed activity. Their application to assess human health impacts within EIA requires linkage to one of the mentioned direct or complex health indicators via casual pathways.

The two potentially relevant indicators are natural disasters and vulnerability to poverty (SDG indicator number 1.5.1) and maternal mortality (3.1.1). The first one is considered potentially relevant for EIA depending on the subject of the development activity, as well as the geographical and social conditions of the population in the target area of activity. Maternal mortality can be relevant for use in EIA, if the activity influences either social conditions, such as education, or the health system and access to health services in a target area. Environmental factors, which could be a part of the relevant risk factors for maternal mortality, are directly addressed by enlisted indicators.

\section{DISCUSSION}

Addressing human health within EIA processes is a window of opportunity to strengthen the human health agenda within developmental processes at all levels (global-local as continuum). EIA, contrary to health impact assessment (HIA), is a statutory process in most countries of the world and, as such, directly links both to governance and to economic decision making (e.g., financial sectors and loans). Inclusion of SDG indicators as outcome indicators in assessment processes could prove to be mutually complementary. It may better align new projects with SDGs and, at same time, offer a more standardized approach to conducting population health assessment that is more encompassing of the international and normative policies defining future development. A conceptual framework presented by Kørnøv et al. [12] divides SDGintegration into various levels, differentiating between nonintegration, conservative integration and radical integration. Drawing upon SDG indicators when measuring impact on health parameters in EIA would help to substantiate SDG-integration within, at minimum, the third level through conservative integration, in which SDG indicators support scoping and defining significant impacts. However, using SDG-derived health indicators to actively test project impacts or as elements of decision-making throughout the process could allow for the navigation into higher levels of integration.

Another issue where inclusion of SDG indicators might help to address human health impacts within EIA is availability of data. Impact assessment processes are often restricted by a lack of "ready-to-use" data and require specific data collection prolonging the time of assessment [24]. SDG indicator values are collected on national levels and might be available also on a regional or local level. Countries are developing their own data collection frameworks including surrogate indicators as in Denmark for example the "Vores Mall" report [25]. Naturally, these indicators can well be used to describe the baseline levels within EIA reports before implementation of the project. Such a set of indicators can be employed in screening, scoping and risk appraisal phases of assessment processes.

Having a set standard of health outcome indicators for assessment of human health impacts within EIA (but also other types of impact assessments) could invite for a discussion on possibilities to standardize impact assessment process through standardization of indicators. Typology of projects subjected to EIA are usually described in annexes of national legislation providing broad, but to some extent, pre-defined types of developmental activities (e.g., transportation infrastructure projects). On the other hand, national health policies (programs) usually pre-define priority areas of human health measures (e.g. cardiovascular disease, cancer, diabetes). What remains to be done is linking the two ends of impact assessment; having a well-defined (standard) set of health outcome indicators could substantially enhance quality of assessment processes. Such standard set of indicators could also contribute to important workforce issues. Human health expertise should always be part of the impact assessment process and having a standard set of outcome indicators can better specify what kind of expertise is necessary to involve.

\section{Conclusion}

Impact assessment processes became a significant and positive tool to protect the environment as well as human health, even though the original scope in legislation was oriented towards environmental protection. Recent changes in legislation especially within Europe opened a window of opportunity for improved targeting of human health impacts within EIA. At the same time, the global effort towards the achievement of SDGs as a 
guiding policy ambition opens the issue of integration of SDGs into impact assessment processes. Our short paper outlines possibilities and potential benefits of such integration on the indicator level and also proposes those indicators that may be relevant for consideration in Danish EIA practices.

\section{AUTHOR CONTRIBUTIONS}

GG and NK conceptualized the manuscript and developed the human health part. EB contributed by SDG indicator subject and IL and LK added the environmental assessment part. GG developed the first draft ad all co-authors edited it.

\section{REFERENCES}

1. Morgan RK. Environmental Impact Assessment: The State of the Art. Impact Assess Project Appraisal (2012) 30:5-14. doi:10.1080/14615517.2012.661557

2. Mekouar A. UN Environment, Assessing Environmental Impacts-A Global Review of Legislation. Nairobi, Kenya: Revue juridique de l'environnement (2018). p. 659-60.

3. Bhatia R, Wernham A. Integrating Human Health into Environmental Impact Assessment: An Unrealized Opportunity for Environmental Health and Justice. Environ Health Perspect (2008) 116:991-1000. doi:10.1289/ehp.11132

4. Union E. Environmental Impact Assessment, Directive 2014/52/EU Vol OJ L 124. Brussels, Belgium: European Union (2014).

5. Danish EIA Law. Bekendtgørelse Af Lov Om Miljøvurdering Af Planer Og Programmer Og Af Konkrete Projekter (VVM). Law Number 1225 The Danish Parliament, Copenhagen, Denmark (2018). Availabe at: https://www. retsinformation.dk/Forms/R0710.aspx?id=203447\#idcc7ca7b9-afba-42a08bb4-262b1b3a91ac (accessed on 07 06, 2021).

6. Kørnøv L. Health in SEA of Spatial Planning: The Danish Guidance and Practice. In: J Nowacki, M Martuzzi, TB Fischer, editors. Health and Strategic Environmental Assessment. Rom, Italy: World Health Organization (2010). p. 46-50.

7. Humboldt-Dachroeden S, Fischer-Bonde B, Gulis G. Analysis of Health in Environmental Assessments-A Literature Review and Survey with a Focus on Denmark. Int J Environ Res Public Health (2019) 16:4570. doi:10.3390/ijerph16224570

8. Harris P, Viliani F, Spickett J. Assessing Health Impacts within Environmental Impact Assessments: an Opportunity for Public Health Globally Which Must Not Remain Missed. Int J Environ Res Public Health (2015) 12:1044-9. doi:10. 3390/ijerph120101044

9. Cave B, Claßen T, Fischer-Bonde B, Humboldt-Dachroeden S, MartínOlmedo P, Mekel O, et al. Human Health: Ensuring a High Level of protectionA Reference Paper on Addressing Human Health in Environmental Impact Assessment: As Per EU Directive 2011/92/EU Amended by 2014/52/EU. International Association for Impact Assessment and European Public Health Association (2020).

10. Ahmad BS. Integrating Health into Impact Assessment: Challenges and Opportunities. Impact Assess Proj Assess (2004) 22 1:2-4. doi:10.3152/ 147154604781766094

11. Dreamsproject. Dreamsproject (2021). Available at: www.dreamsproject.dk (last accessed 07 06, 2021).

12. Kørnøv L, Lyhne I, Davila JG. Linking the UN SDGs and Environmental Assessment: Towards a Conceptual Framework. Environ Impact Assess Rev (2020) 85:106463. doi:10.1016/j.eiar.2020.106463

13. Sebestyén V, Bulla M, Rédey Á, Abonyi J. Network Model-Based Analysis of the Goals, Targets and Indicators of Sustainable Development for Strategic Environmental Assessment. J Environ Manag (2019) 238:126-35. doi:10.1016/ j.jenvman.2019.02.096

14. González Del Campo A, Gazzola P, Onyango V. The Mutualism of Strategic Environmental Assessment and Sustainable Development Goals. Environ Impact Assess Rev (2020) 82:106383. doi:10.1016/j.eiar.2020.106383

\section{FUNDING}

This work was supported by grant 0177-000218 DREAMS provided by Danish Innovation Fund.

\section{CONFLICT OF INTEREST}

ERB was partially employed by COWI.

The remaining authors declare that the research was conducted in the absence of any commercial or financial relationships that could be construed as a potential conflict of interest.

15. Ravn Boess E, Kørnøv L, Lyhne I, Partidário MR. Integrating SDGs in Environmental Assessment: Unfolding SDG Functions in Emerging Practices. Environ Impact Assess Rev (2021) 90:106632. doi:10.1016/j.eiar. 2021.106632

16. Gulis G. Health Impact Assessment and the Sustainable Development Goals. Health Promot Int (2019) 34(3):373-5. doi:10.1093/heapro/ daz052

17. Green L, Gray BJ, Ashton K. Using Health Impact Assessments to Implement the Sustainable Development Goals in Practice: A Case Study in Wales. Impact Assess Project Appraisal (2020) 38(3):214-24. doi:10.1080/14615517.2019. 1678968

18. Winkler MS, Adongo PB, Binka F, Brugger F, Diagbouga S, Macete E, et al. Health Impact Assessment for Promoting Sustainable Development: The HIA4SD Project. Impact Assess Project Appraisal (2020) 38(3):225-32. doi:10.1080/14615517.2019.1694783

19. Ravn Boess E, Lyhne I, Davila JG, Jantzen E, Kjellerup U, Kørnøv L. Using Sustainable Development Goals to Develop EIA Scoping Practices: The Case of Denmark. Impact Assess Project Appraisal (2021) 39:463-77. doi:10.1080/ 14615517.2021.1930832

20. Hacking T. The SDGs and the Sustainability Assessment of Private-Sector Projects: Theoretical Conceptualisation and Comparison with Current Practice Using the Case Study of the Asian Development Bank. Impact Assess Project Appraisal (2019) 37:2-16. doi:10.1080/14615517.2018. 1477469

21. Unstatus. Global Indicator Framework for the Sustainable Development Goals and Targets of the 2030 Agenda for Sustainable Development (2020). Available at https://unstats.un.org/sdgs/indicators/Global\%20Indicator\%20Framework \%20after\%202021\%20refinement_Eng.pdf (accessed 07 07, 2021).

22. IHME. Health-related SDGs Overview (2017). Available at: http://ghdx healthdata.org/sites/default/files/record-attached-files/IHME_GBD_2017_ HEALTH_SDG_1990_2030_OVERVIEW_Y2018M11D08.PDF (accessed on 06 25, 2021).

23. World Health Organisation. International Classification of Diseases (2021). Available at: https:/www.who.int/standards/classifications/classification-ofdiseases (last accessed 07 06, 2021).

24. Dannenberg AL. Effectiveness of Health Impact Assessments: A Synthesis of Data from Five Impact Evaluation Reports. Prev Chronic Dis (2016) 13:E84. doi:10.5888/pcd13.150559

25. Gør Verdensmål til Vores Mål. (2020). Copenhagen ISBN 978-87-501-2359-0 (in Danish only). Available at: https://www.dst.dk/da/Statistik/Sdg/aktiviteter/ danske-maalepunkter. (Accessed January 10, 2021).

Copyright (C) 2022 Gulis, Krishnankutty, Boess, Lyhne and Kørnøv. This is an openaccess article distributed under the terms of the Creative Commons Attribution License (CC BY). The use, distribution or reproduction in other forums is permitted, provided the original author(s) and the copyright owner(s) are credited and that the original publication in this journal is cited, in accordance with accepted academic practice. No use, distribution or reproduction is permitted which does not comply with these terms. 